\title{
Demand Side Management: Demand Response, Intelligent Energy Systems, and Smart Loads
}

\author{
Peter Palensky, Senior Member, IEEE, and Dietmar Dietrich, Senior Member, IEEE
}

\begin{abstract}
Energy management means to optimize one of the most complex and important technical creations that we know: the energy system. While there is plenty of experience in optimizing energy generation and distribution, it is the demand side that receives increasing attention by research and industry. Demand Side Management (DSM) is a portfolio of measures to improve the energy system at the side of consumption. It ranges from improving energy efficiency by using better materials, over smart energy tariffs with incentives for certain consumption patterns, up to sophisticated real-time control of distributed energy resources. This paper gives an overview and a taxonomy for DSM, analyzes the various types of DSM, and gives an outlook on the latest demonstration projects in this domain.
\end{abstract}

Index Terms-Building automation, demand response, demand side management (DSM), energy efficiency, energy management, IEC 61850, load management, peak shaving, smart grids.

\section{INTRODUCTION}

$\mathbf{T}$ HE CLASSICAL modus operandi of electric energy systems is unidirectional and top-down oriented. A limited number of large power plants feed into the grid and try to keep demand and supply balanced at all times. This balance is a very crucial aspect in operating an electric energy system. Volatile renewable energy sources [1] and electro-mobility are new challenges to this balance and call for sophisticated control methods [2].

Using the load as an additional degree of freedom is not entirely new but affordable global communication infrastructure and embedded systems make it now relatively easy to add a certain portion of "smart" to the loads. The development is driven by the fact that-despite increased efficiency of electric devices - consumption is steadily rising some percent every year. While generation might not be much of a problem, it is the grid capacity that makes many involved people worry.

Especially new and ambitious projects, like DeserTec (extensive solar power stations in Northern Africa to supply Europe), and large offshore wind parks in the Northern Sea, raise questions about the transport of energy. The grids might soon face their limits, and intelligent Demand Side Management (DSM) is one way to stretch these limits a bit further. DSM also promotes

Manuscript received February 27, 2011; revised May 05, 2011; accepted May 18, 2011. Date of publication June 27, 2011; date of current version August 10, 2011. Paper no. TII-11-080.

P. Palensky is with the Austrian Institute of Technology, Energy Department, 1210 Vienna, Austria (e-mail: palensky@ieee.org).

D. Dietrich is with the Vienna University of Technology, 1040 Vienna, Austria (e-mail: dietrich@ict.tuwien.ac.at).

Color versions of one or more of the figures in this paper are available online at http://ieeexplore.ieee.org.

Digital Object Identifier 10.1109/TII.2011.2158841

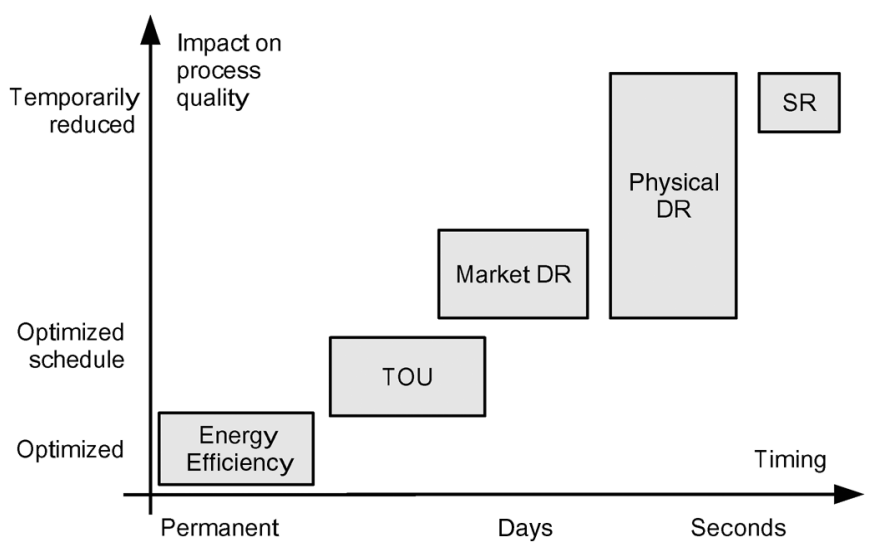

Fig. 1. Categories of DSM.

distributed generation: In order to avoid long-distance transport, locally generated energy could be consumed by local loads, immediately when it is available. DSM's main advantage is that it is less expensive to intelligently influence a load, than to build a new power plant or install some electric storage device.

DSM includes everything that is done on the demand side of an energy system, ranging from exchanging old incandescent light bulbs to compact fluorescent lights (CFLs) up to installing a sophisticated dynamic load management system. While DSM was "utility driven" in the past, it might move a bit towards a "customer driven" activity in the near future.

Reference [3] shows the utility point-of-view. The authors perform a sequential Monte Carlo simulation to assess the impact of stochastic grid component outages and how far DSM can help in these cases. The correlation and sensitivity of the component capacity variation to the expected shortage of available transmission capacity is identified as well as the contribution of DSM to transmission capacity. Such centralized structures are sometimes complemented (if not replaced) by flat and freely organized market-driven mechanisms [4].

Depending on the timing and the impact of the applied measures on the customer process, DSM can be categorized into the following (see Fig. 1).

a) Energy Efficiency (EE).

b) Time of Use (TOU).

c) Demand Response (DR).

d) Spinning Reserve (SR).

The "quicker" changes are processed and done, the more unwanted impact they potentially have onto the customers' processes. The "processes" can be manufacturing output, pump power or even optimizing human comfort or health in a building. 


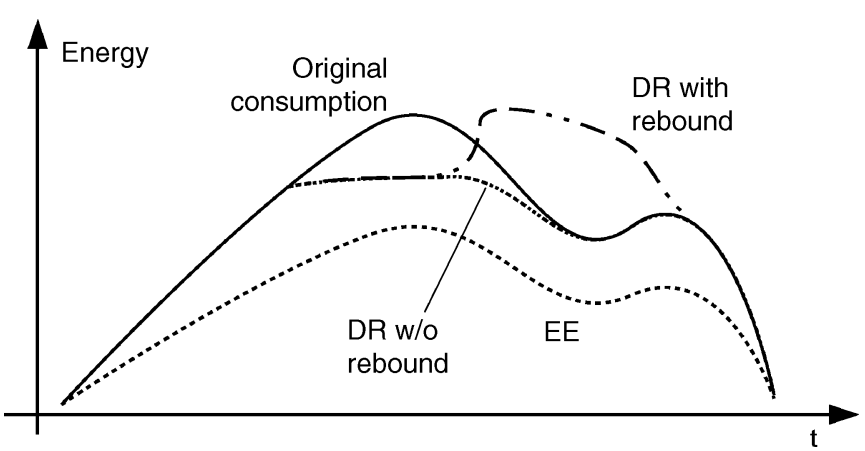

Fig. 2. Impact of improved energy efficiency versus demand response.

The lower edge of the DSM spectrum is energy efficiency measures. They include all permanent changes on equipment (e.g., exchanging an inefficient ventilation system with a better one) or improvements on the physical properties of the system (e.g., investing in the building shell by adding additional insulation). Such measures result in immediate and permanent energy and emissions savings and are therefore the most welcome method. Sometimes seen as a separate category of DSM, Energy Conservation (EC, [5]) shall be seen as part of Energy Efficiency in this paper. EC focuses on users and behavioral changes to achieve more efficient energy usage.

Time of use tariffs penalize certain periods of time (e.g., 17:00-19:00) with a higher price, so customers (re)arrange their processes to minimize costs. A change in the TOU price-schedule means a change in a supply contract/tariff and, therefore, does not happen on a frequent basis. [6] shows that combining DSM and TOU tariffs significantly increases security and lowers costs and emissions of energy systems with a high share of wind power.

Dynamic DSM does not necessarily reduce energy consumption, only consumption patterns are influenced. If a process is interrupted for some reason, it might have to "catch up" once it has green lights again. An example is a water pumping system that can-because of its storage tanks-easily be shed for $30 \mathrm{~min}$. After the shed it has to fill up its tanks again, since they were drained during the shed period. A so-called "rebound effect" (or payback) takes place, energy is typically not saved and maybe even a new peak is generated (see Fig. 2).

Sometimes this effect can be avoided, but it might result in a reduced process quality. Such an ideal "peak shaving" applied to a ventilation system would mean that if it normally ran at $50 \%$ and were shed for half an hour, it is prohibited to compensate that downtime with half an hour of $100 \%$.

Reference [7] distinguish between the following.

a) Incentive-Based DR.

- Direct load control (DLC): utility or grid operator gets free access to customer processes.

- Interruptible/curtailable rates: customers get special contract with limited sheds.

- Emergency demand response programs: voluntary response to emergency signals.

- Capacity market programs: customers guarantee to pitch in when the grid is in need.
- Demand bidding programs: customers can bid for curtailing at attractive prices

b) Time-Based Rates DR.

- Time-of-use rates: a static price schedule is applied.

- Critical peak pricing: a less predetermined variant of TOU.

- Real-time pricing (RTP): wholesale market prices are forwarded to end customers.

Reference [8] distinguishes the following.

- Level I: Load shape objective.

- Level II: End use, technology alternatives, and market implementation methods.

An alternative way to look at the various flavors of demand response is to distinguish between the following.

- Market DR: real-time pricing, price signals and incentives, and

- Physical DR: grid management and emergency signals.

Market DR relies on certain market places where prices are formed and products are traded. Such market places are not arbitrarily quick, which is why most transactions are done a day ahead. An exception is real-time pricing (RTP), where the figures of an energy spot market (e.g., EEX-European Energy Exchange in Leipzig) are forwarded to end users without delay. A typical way to analyze and optimize market mechanisms is System Dynamics (SDs). Reference [9] shows an SD approach for designing energy prices for DSM. The price is split into a capacity and a quantity part, a government-driven policy is derived.

Reflecting grid congestion or an excess supply of wind power onto the price can provoke stabilizing customer behavior. This misleads some people to believe that monetary incentives like RTP could solve all existing problems of the energy grid. However, limited customer elasticity and physical situations that are not mapped onto prices lead to the fact that real load shedding for grid relief cannot be done via prices alone.

This is where physical DR comes into play. It sends out binding requests for demand management if the grid or parts of its infrastructure (power lines, transformers, substations, etc.) are in a reduced performance due to maintenance or failure.

A good mixture of both market and physical DR is usually necessary to run a grid optimal.

Spinning Reserves (SR), implemented by loads, represent the upper (i.e., quick) end of the DSM spectrum. Unfortunately, the term itself is used in a loose way across the power community. In this paper, spinning reserve is seen as primary (active power output directly depends on frequency) and secondary control (restoring frequency and grid state with additional active power) [10]. This is typically the task of regulation power plants. Loads can act as "virtual" (or negative) spinning reserve if they correlate their power consumption to the grid state in a "droop control" or some other smart manner. In its easiest way, devices use less power if frequency drops (Fig. 3).

This can happen in an autonomous way (similar to primary control) or in a coordinated way (similar to secondary control). Depending on the type of DSM, different means of technology and especially communication are necessary.

Comparing the various flavors of DSM, it is clear that EE is most wanted. It saves energy and emissions, while most of the 


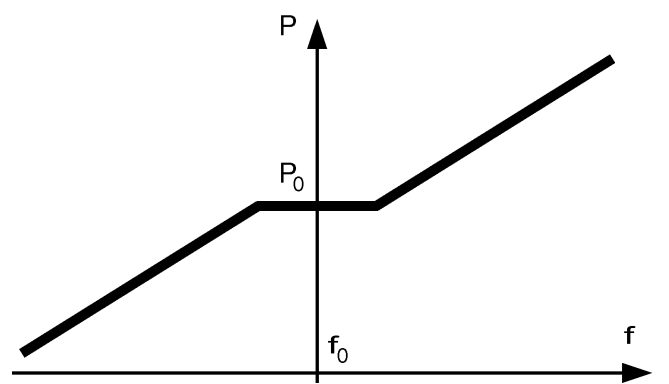

Fig. 3. A cooperative consumer backs off when grid frequency decreases.

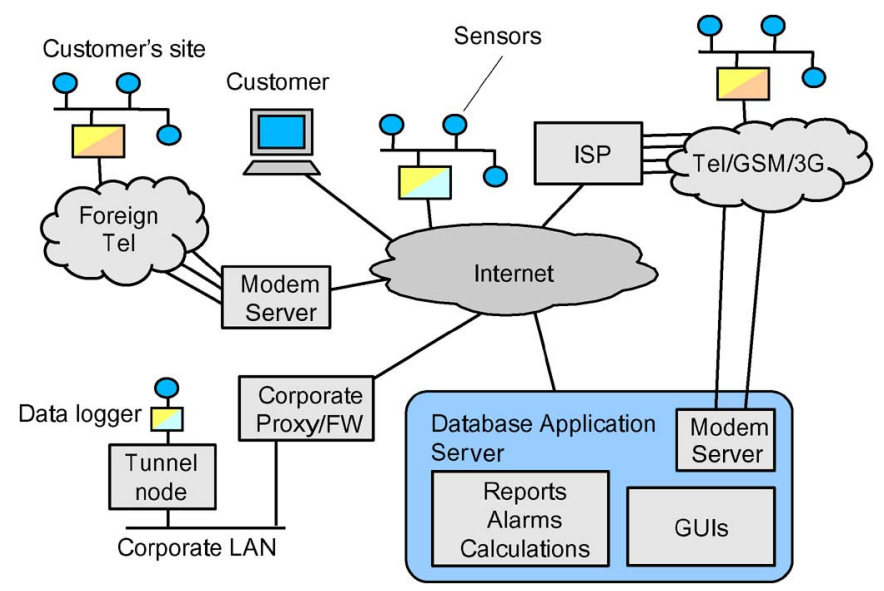

Fig. 4. A web-based energy information system, based on [11].

other types just shift it in time. So, the first goal must always be to improve efficiency. After that, the dynamics can be optimized. Depending on the boundary conditions (electro-technical setting, market setting, capabilities of the system) of the system, one or the other dynamic DSM method might be chosen. Naturally, the break-even point of automation investments and financial incentives determines how far one can go.

\section{Demand Side Management}

\section{A. Energy Efficiency}

Improving energy efficiency of buildings or industrial sites starts with information and insight into the processes involved. Practically, every customer site has hidden problems that waste energy: compressed air leakages, misconfigured controls, dirty filters, broken equipment, etc. Actually, such trivial problems are often overlooked, unless a tool for analyzing energy efficiency like [11] is used. The typical parts of such an Energy Information System (EIS, Fig. 4) are as follows.

- Data acquisition infrastructure (sensor networks, data loggers, gateways, modems, etc.).

- An application server with database, calculation and analysis algorithms, alarming and reporting.

- User interfaces for visualization and configuration.

The classical calculations are as follows.

- Baseline versus peak load comparison: a high baseline might stem from standby power or old equipment (e.g., bad insulation).

- Weekly comparison of time series: often lighting or ventilation accidentally runs through the night and the weekend.

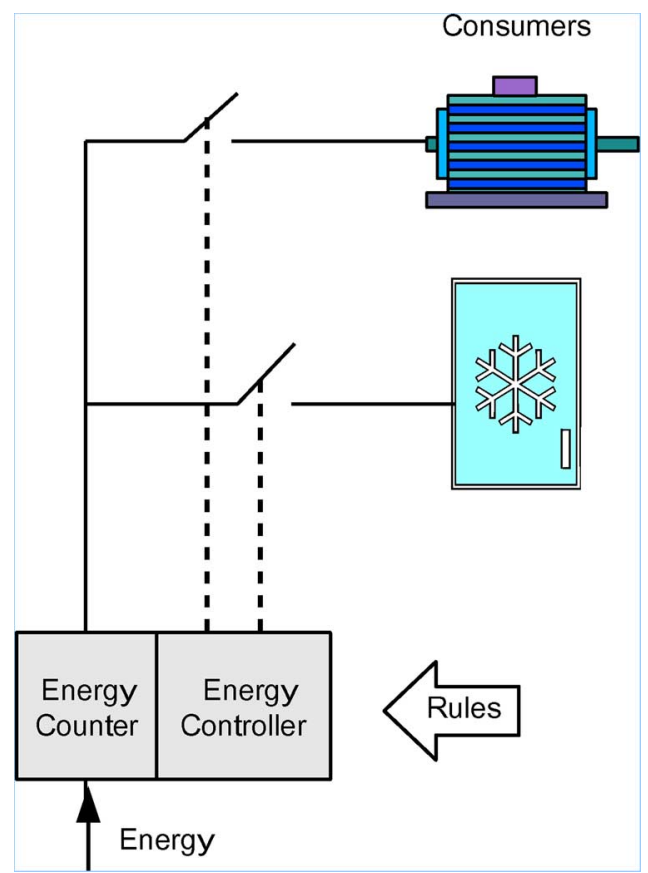

Fig. 5. An energy controller switches (off) devices.

- Benchmarks: compare your performance to others, especially useful for multisite customers (e.g., supermarket chains).

- Process correlations: does your energy consumption strongly correlate with, for instance, the outside temperature or solar gains?

Beside such static efficiency figures, it is also the dynamics that gets evident with such systems. An experienced facility manager or a smart algorithm can interpret consumption patterns and find ways to reduce peak loads. If the energy supply contract penalized peaks, this would be a valuable result. If changes to the logistics cannot help, automation equipment might be necessary.

\section{B. Energy Controllers}

If the operations of equipment needs consumption-driven adjustment, an energy controller could be used. Such a device is typically located at the energy meter and monitors the consumption trend. If the trend points to unwanted levels, the controller switches off equipment, based on certain priorities and other rules (Fig. 5).

Configuring such an energy controller can be a very complex task. Especially if consumers are added or removed, the stability depends on a wise choice of rules. One simple example of how to determine the priority level depending on the consumption trend is shown in Fig. 6. The graphic shows one "measurement period" (country-dependent time of usually 15 or 30 min that represents the smallest time period for billing purposes). Each period, the trend starts from zero and moves monotonously upwards. The more power is consumed (bottom curve), the steeper the energy consumption curve.

Once the consumption trajectory crosses one of the upper threshold lines, certain classes (or groups, priorities) of con- 


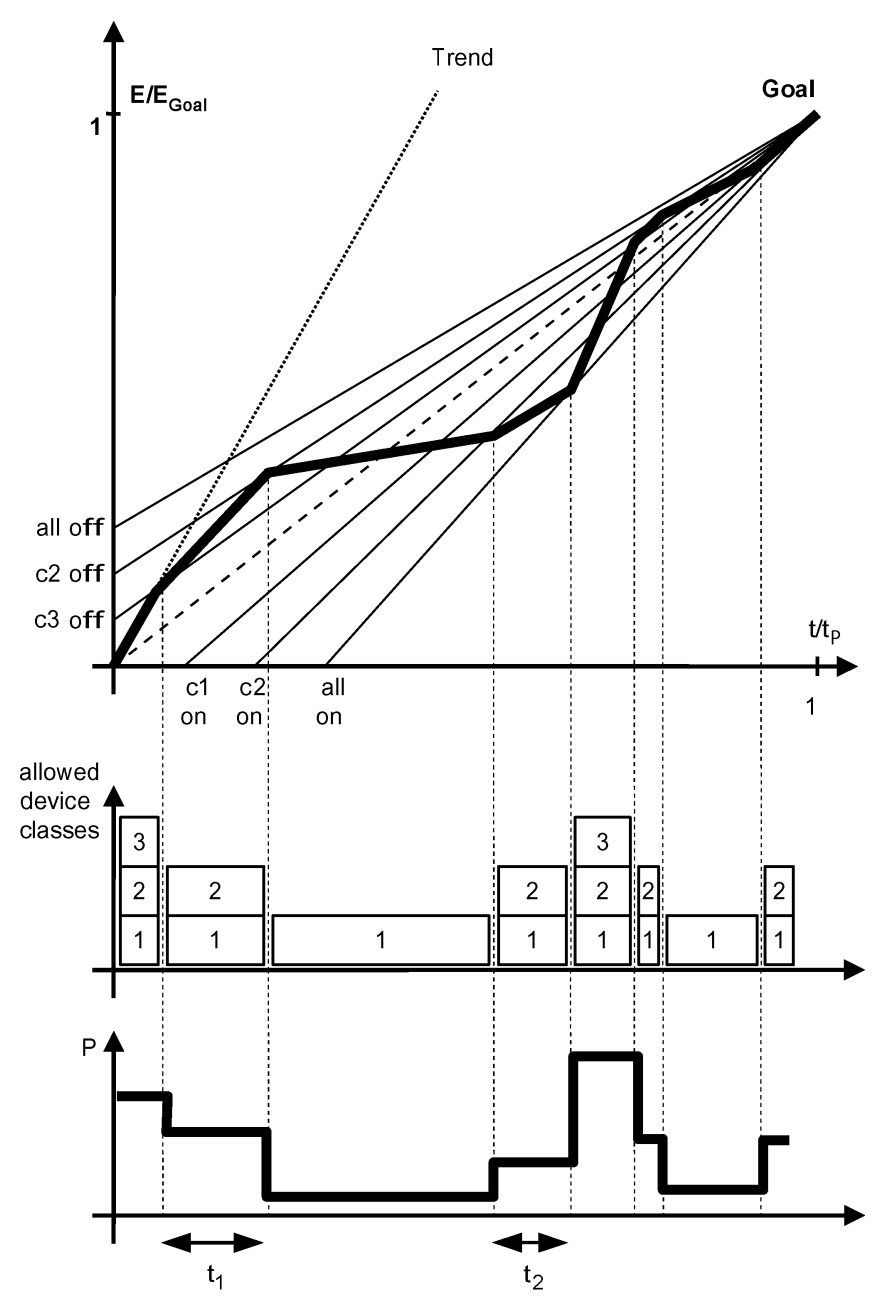

Fig. 6. Selection of priorities in a maximum demand monitor.

sumers are switched off (or duty-cycled, etc.). Fig. 6 assumes three device classes, $\mathrm{c} 1$ the most important ones, $\mathrm{c} 3$ the least important ones. The trajectory starts steep since all devices are allowed on initially. It is steeper than the ideal (dashed) curve so it necessarily crosses "c3 off" which turns off the least important ones as a first measure to flatten the curve. In this example, this is not sufficient so it crosses "c2 off" after some time and also class 2 devices are switched off: only category 1 devices are allowed on now. The resulting (too) flat curve crosses "c1 on" which has no effect since $\mathrm{c} 1$ devices were allowed on anyway. Crossing "c2 on" allows class 2 devices on again and so forth. "all off" would result in $\mathrm{P}=0$ and a horizontal energy trajectory. With such a system, the consumption trajectory will (if physically possible) reach the goal at the end of the period.

Note that the power consumption during $t_{1}$ and $t_{2}$ is different although both intervals say "allowed devices classes are 1 and 2." This demonstrates the fact that devices in one category may be switched on but do not have to, since they have their own, independent controls and schedules.

The goal can also change from period to period. With this, a given load chart can be followed, always assuming that the process physically allows that.

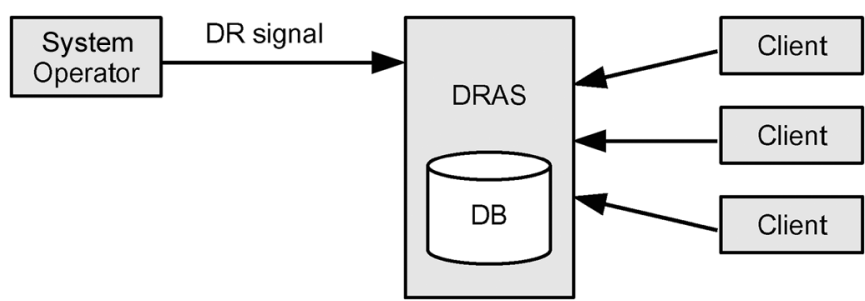

Fig. 7. OpenADR clients and the system operator connect to the DRAS.

\section{Demand Response}

A much quicker response is provided by the many flavors of Demand Response (DR). Typically, a signal is broadcast, e.g., by the distribution or transmission system operator (DSO/TSO). This signal might contain a price or a command for load shedding/shifting. The deadline is not necessarily instantaneous: the signal might refer to a situation next day at 12:00 noon since often grid emergencies can be anticipated.

Classical Direct Load Control (DLC) assumes that loads are fully under control, i.e., they do what they are told to do. All intelligence is expected in the controller, who ideally uses load models to make reasonable decisions. Reference [12] used a stochastic state-space model for loads and simulate an urban power system. The results show savings both in costs and transport losses.

One modern system for automated demand response, OpenADR [13], [14], is developed by the leading research group on DR, the Demand Response Research Center (DRRC) at the Lawrence Berkeley National Laboratory. OpenADR is an open specification and an open-source reference implementation of a distributed, client-server oriented DR infrastructure with a publisher-subscriber model. Its main components are the following (Fig. 7).

- Demand Response Automation Server (DRAS).

- DRAS Clients at the customers' sites.

- The Internet as communication infrastructure.

The client side is often just a communication library, used by controls manufacturers to make their product OpenADR-capable. Clients can subscribe to DR "programs," like critical peak pricing or demand bidding, and the DRAS serves as simple market platform and subscription manager. It keeps a database of the participating clients and the program that they are subscribed to.

If, for instance, a utility or system operator issues an emergency message to the DRAS, the server forwards the message to all clients that participate in the "emergency program." Transactions need to be recorded by the DRAS since financial incentives are connected with reacting to such events.

The above system is almost open-loop control, since neither load models nor online feedback is used. Reference [15] combines ripple control ${ }^{1}$ with a wide area phasor measurement system, based on global positioning system (GPS) timestamps used by distributed voltage/current measurement equipment. The result of adding this feedback loop is wide area control for energy systems. Assuming 10\% of the loads as controllable

\footnotetext{
${ }^{1}$ Broadcasting powerline signals at nighttime for electric storage stoves.
} 
via ripple control, the authors estimate approximately $30 \%$ savings in transmission corridor losses and approximately $40 \%$ in control power savings.

Reference [16] analyzes the business impacts of DSM. Four business models are analyzed and a district of 300 households with three different types of electric devices are simulated: loads with storage (e.g., boiler), shiftable loads (e.g., dishwasher), and real electric storages (e.g., batteries). The focus is on the district level, i.e., making a district more self-sustainable with regards to power consumption, and is entirely market based. It is shown that flexible loads can be very attractive for DSOs when used for substation-level peak shaving.

\section{Distributed Spinning Reserve}

Distributed spinning reserve tries to support the traditional providers of ancillary services by imitating their behavior. On the demand side, this means that load can be reduced or increased when the grid frequency drops or rises.

Two implementations of this scheme are the Integral Resource Optimization Network (IRON) [17] and the "gridfriendly controller" [18]. Both measure the frequency and react on it. The difference is that the IRON box has an additional communication interface (a GSM/3G modem) that allows cooperative algorithms.

A simple example for such an add-on feature due to its communication capabilities is fairness. If, for example, a number of devices can shed their load, and already one of them shedding is sufficient, it might always be the quickest that wins the monetary incentive. With communication, it can be arranged that all of them have their turn. Such coordination also contributes to stability. Imagine a community of autonomous, distributed controllers without communication. All of them reacting on grid problems in the same manner is the perfect recipe for instabilities. They will have do it one after another to avoid a too strong reaction.

All this is distributed, but still classical control: The frequency needs to drop so that controllers react, and it needs to be restored so that they stop fixing it. A slightly more sophisticated version goes into model-predictive controls. A device that has a load model of itself might predict how much/long it can shed load until it has to stop shedding for process reasons. Load models are the second step towards stability. They give the answer to the question of how strong the reaction to an (anticipated) problem needs to be and who can provide it.

\section{E. Demand Shifting}

Load models are also used when demand needs to be shifted to other times. If the weather and other forecasts predict a grid emergency at 17:30 the next day, intelligent consumers can plan ahead and -if their process allows it-do their tasks earlier or later. Examples are precooling, producing for the stock, etc. Processes that can be shifted typically belong to one of the following categories.

- Inert thermal processes (heating, cooling).

- Inert diffusion processes (ventilation, irrigation, etc.).

- Mass transport (pumps with tanks, conveyor belts, etc.).

- Logistics (schedules, dependencies, lunch-breaks, etc.).
Shifting load to a later point in time (i.e., postponing) is easy. The load is shed at the critical time and the process has to catch up later. Unfortunately, the process quality is not guaranteed: If there are not enough products on stock or if the tank is almost empty, the process might run into troubles during the shed time. It is therefore better to move the peak before the shed time and be prepared. For this, load models are needed. They predict how long things can be turned off, how much it takes to fill the "virtual storage," and what it costs [19].

The "virtual storage" of Demand Shifting can of course be enhanced by special means. [20] for instance add phase change material to buildings with electric heating to increase the low thermal inertia of the structure.

\section{F. Loads as Virtual Storage Power Plants}

Virtual Power Plants (VPPs) are a community of typically smaller generation units (often renewable energy sources) that appear as one power plant to the grid management [21]. The (typically distributed) equipment needs to be controlled from a central dispatch and management node, and modern SCADA standards like IEC 61850 [22] are used to integrate the individual parts.

A special case arises if these parts are loads. Loads cannot generate, they can only act as virtual storage via load shifting. Aggregating many of such loads leads to sizes that can participate on power markets and compete with traditional electric storage [23]. Typically, aggregators use proprietary technology to do this, but IEC 61850 is a good candidate to enable interoperability.

The most crucial point of VPPs is even more crucial with load-based virtual storage power plants: guaranteed availability. If the grid operator requests a certain amount of regulation power it must be delivered. Unfortunately, many loads behave in a stochastic manner. A customer process might just at that time not be interruptible or its virtual storage might be empty. For this, again, reliable load models are necessary so that the VPP operator can keep its promises available.

\section{G. Communication Protocols for Load Management}

IEC 61850 is a standards series for substation automation. It contains an addressing scheme for "Intelligent Electronic Devices" (IEDs) or Distributed Energy Resources (DERs) and their properties and functions, an XML-based substation configuration language, communication protocols for best-effort and realtime transport, and much more. Modern manufacturers implement this technology in their latest power engineering products like distribution automation nodes or grid measurement and diagnostics devices. It is popular for implementing VPPs and gradually makes its way down to the distribution level.

Coming from the other edge of the system, home and building automation systems move towards the energy business. Smart domestic controls can cause significant energy savings, [24] report $40 \%$ energy savings via enhanced lighting controls. The current question is how to unify the various devices from a controls perspective?

Several technology groups have published standards for energy services in the home. One of them is the Zigbee Smart Energy Profile [25], an extensive document that describes a large 


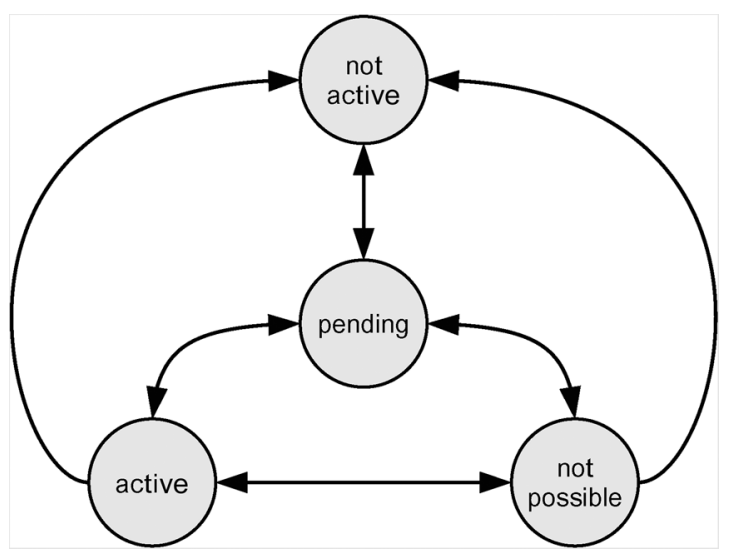

Fig. 8. The states of the BACnet load control object (simplified).

number of services like meter reading, online pricing, information security, or load control. A shorter but nevertheless interesting proposal comes from the American Society of Heating, Refrigerating and Air Conditioning Engineers (ASHRAE), the BACnet ([26]) load control object (specified in an addendum to the ISO BACnet standard [27]). It defines an abstract state machine that represents a load with (or without) load shedding capabilities (Fig. 8).

A device can be queried for its state. "Not active" means it is capable of shedding and might receive a shed command which would put it into state "pending" until the shed is fully done. If the device enters the "not possible" state, it cannot shed (anymore). This simple finite-state machine (FSM) is an abstract way of representing electric consumers. With this, very different devices can be addressed by a (central) decision unit in a unified way.

Another project in the home-domain is KNIVES, a treetopology demand management system, developed at Keio University, Japan. It reacts on energy prices and influences loads, based on priorities. For integration with home automation infrastructure, a wireless interface is used [28]. KNIVES uses embedded systems with dry contacts and relays, installed at the customer's premises to take influence on electric loads. A utility company or system operator can then dispatch messages via the tree-like, Internet-based network of servers.

There is no unified DSM communication protocol (yet), different domains like utilities, research or automation companies have introduced their solutions and fight for dominance. OpenADR and IEC 61850 receive broad acceptance so we might see the first aspects of established standards soon.

\section{RECENT DEMONSTRATIONS}

Two interesting demonstration projects are done within the "SmartGrids Model-Region Salzburg": Building-to-Grid (B2G) and Consumer-to-Grid (C2G). The two projects aim at two different aspects with regards to an intelligent demand-side: the automated processes in a building and the customer him/herself.

B2G integrates building automation systems into an intelligent community of cooperating software agents. The smart grid (operator) can interact with this community to negotiate consumption patterns or ask for support in the case of an emergency.

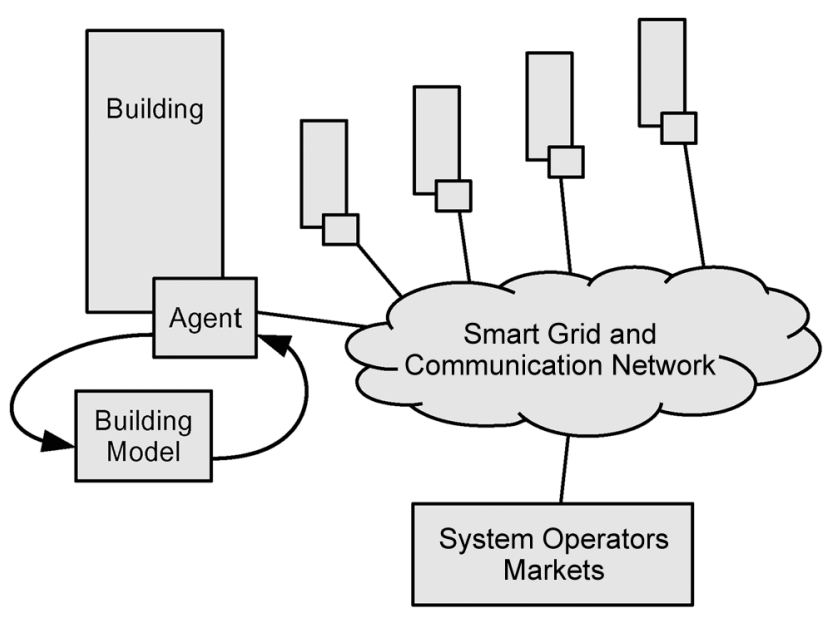

Fig. 9. Software agents represent and manage buildings in the building-to-grid project.

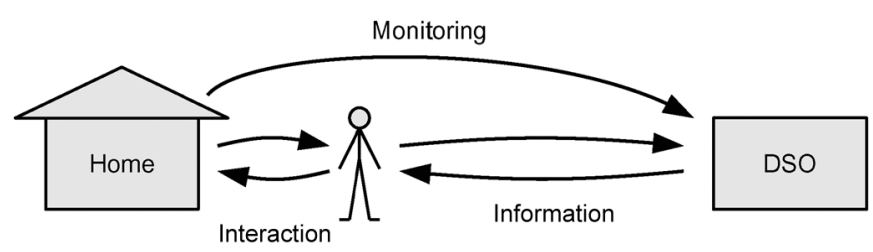

Fig. 10. The consumer-to-grid project puts the human back into "the loop."

The important aspect of $\mathrm{B} 2 \mathrm{G}$ is, that the agent has a local "world model." It is equipped with a learning model of the building's processes. With this model, the agent can plan ahead since it knows typical usage patterns, time constants of the equipment and the building itself, and it can even test alternative behavior in advance (Fig. 9). It is important that this model can be learned during runtime, since it is impossible to manually configure all buildings in the field trial.

The target application for B2G is physical and marked-oriented demand response. An example for physical DR in this project is supporting the DSO in keeping the voltage levels on the grid, an example for market-oriented DR is real-time pricing.

The Consumer-to-Grid project enables a part in this system that was long forgotten: the human factor. Control engineers categorize humans and human behavior typically as "disturbance" or stochastic variable. In the case of the energy system, humans can provide remarkable local intelligence if they are included in the right way. On the other side, any technology is doomed to fail if the involved users do not like or understand it: Two reasons for $\mathrm{C} 2 \mathrm{G}$ to analyze the potential and the mechanisms of human involvement in the energy demand.

A large number of utility customers are clustered in groups according to certain statistical rules: categories like "double income no kids" are used to isolate demographic differences, control groups are created, geographic and social spread is considered, etc. All probands are equipped with a smart meter to get fine-grained energy consumption data (Fig. 10).

The probands are then exposed to different types of communication, ranging from personal conversations, letters, smartphone applications, and displays that are installed beside the elevator. All these communication channels supply the customers 
with information about their energy consumption, sometimes in comparison to others. The project analyzes the impact of different types of information, different channels of communication and how long the impact (energy efficiency increase and a load shifting) lasts. Such "soft" DSM is proven to work [29], the question is what works best and what is the right medium, since the way in how we communicate changes constantly.

Both projects are embedded in a larger project bundle that also covers ICT synergies and market/application platforms. First, results of B2G and $\mathrm{C} 2 \mathrm{G}$ are expected for 2012.

A related project on the European level is EcoGrid EU, 2 a large-scale demonstration project for smart grids and modern ICT-based energy systems. An entire island (Danish Bornholm) will be equipped with intelligent buildings, electric storages, electric vehicles, and distributed generation, all connected with and cooperating via a new type of real-time market platform. For the first time, real-time control issues and market-based price formation have a common ground. Usually, marked-driven DSM relies on the elasticity of the customer with regards to energy prices. The more flexible the demand side, the quicker and stronger a response [30]. EcoGrid EU explicitly combines DLC and marked-based settlement. This accounts for solving multiobjective problems that a DER faces when entering a new energy market. A grid segment might signalize overload, the prices might be attractive and local schedules might add a third voice in the mind of the local DER controller. EcoGrid EU's real-time market might be able to solve parts of these dilemmas. Results are expected in 2013.

Further exciting insights are expected from the German E-Energy project initiative, ${ }^{3}$ where six large projects deal with "prosumers" (grid participants that are sometimes producers or consumers), new service providers, ICT gateways, and renewable energy. Loads and load management play important roles in these projects.

\section{OUTLOOK}

DSM is experiencing a renaissance, driven by the approaching smart power grids, microgrids [31] and supergrids [32]. While microgrids obviously (because of their scarce resources) need a flexible demand side to ease system operation, supergrids import this need from offshore wind farms.

One of the main challenges for DSM is on the ICT side [30]. Surely, DSM potential and operations of the physical parts are important but they are relatively well researched. It is ICT interoperability, algorithm stability, information security, and (information) network management that shows the highest levels of activities. Several international committees are working on smart grid interoperability, smart metering standards, and information security for energy management ([33], [34]).

Out of the classical information security needs, it is the most popular one - confidentiality — which seams to be the least critical one for energy systems.

- Confidentiality: keep my shed-actions private.

- Integrity: be sure to get the correct shed signals.

- Authenticity: be sure of the origin of shed information.

${ }^{2}$ www.eu-ecogrid.net.

${ }^{3}$ www.e-energy.de.
- Availability: be sure that your DR resources are there when you need them.

- Access-control: give your DSO access to the ventilation system but not to the lighting.

- Nonrepudiation: prove your DR participant that he did not shed when he should have.

Clearly, all security requirements are important and need to be taken into consideration when designing an ICT-based DSM system. These requirement stretch up to the required market platforms, in the case of freely tradable energy resource. Prosumers and other DERs need a solid "digital identity" to act as business partner on such platforms. Digital signatures, which address the needs "Integrity" and "Authenticity," are the minimum measures that such a system must implement: DERs must be sure whom they are cooperating with (other DERs, energy markets, etc.) and that data is not manipulated. Otherwise, it is easy to join such a DER community and manipulate entire markets. The only comparable case for such scenarios can be found in mobile telecommunication: mobile devices like cell phones use their tamper-proof subscriber identification modules (SIM, defined as secure platform for this application) to implement authentication and other security services. DERs clearly need something comparable.

This is even more evident when the latest trends in electric mobility is taken into the picture. The storage capabilities of electric vehicles can - supposing charging stations are equipped with feedback inverters — offer similar (and even better) services like intelligent loads. Their roaming nature and dispersed ownership, however, makes management and billing a special challenge. Digital identity of each vehicle and changing station is one step towards a flexible usage of this enormous potential.

Generally, DSM moves from isolated usage (large industrial customers that are called via phone for shedding), and old-fashioned ripple control towards a broad, selective, and intelligent usage of demand resources. Market platforms, a regulatory environment that rewards smart consumer behavior, and automation infrastructure are successfully presented in field trials [14], but still need improvement and a broader application in other countries. Several demonstration projects that are currently starting show that there is an active research community in this field, and that industry is already implementing their results.

\section{REFERENCES}

[1] Eurelectric, "The role of electricity," The Union of the Electricity Industry, Bruxelles, Belgium, 2007, Tech. Rep.

[2] M. Prodanovic and T. Green, "High-quality power generation through distributed control of a power park microgrid," IEEE Trans. Ind. Electron., vol. 53, no. 5, pp. 1471-1482, Oct. 2006.

[3] M. Zhou, Y. Gao, and G. Li, "Study on improvement of available transfer capability by demand side management," in Proc. 3rd Int Conf. Electric Utility Deregulation and Restructuring and Power Technologies, DRPT'08, 2008, pp. 545-550.

[4] A. Mohsenian-Rad, V. Wong, J. Jatskevich, R. Schober, and A. LeonGarcia, "Autonomous demand-side management based on game-theoretic energy consumption scheduling for the future smart grid," IEEE Trans. Smart Grid, vol. 1, no. 3, pp. 320-331, Dec. 2010.

[5] F. Boshell and O. Veloza, "Review of developed demand side management programs including different concepts and their results," in Proc. IEEE Transmission and Distrib. Conf. Expo.: Latin America, PES, 2008, pp. 1-7.

[6] V. Hamidi, F. Li, L. Yao, and M. Bazargan, "Domestic demand side management for increasing the value of wind," in Proc. Int. Conf. Electr. Distrib., CICED, China , 2008, pp. 1-10. 
[7] J. Han and M. Piette, "Solutions for summer electric power shortages: Demand response and its applications in air conditioning and refrigerating systems," Refrigeration, Air Conditioning, and Electric Power Machinery, vol. 29, no. 1, pp. 1-4, Jan. 2008.

[8] S. Rahman and . Rinaldy, "An efficient load model for analyzing demand side management impacts," IEEE Trans. Power Syst., vol. 8, no. 3, pp. 1219-1226, Aug. 1993.

[9] H. Yang, Y. Zhang, and X. Tong, "System dynamics model for demand side management," in Proc. erd Inf. Conf. Electr. Electron. Eng., 2006, pp. $1-4$.

[10] J. Vasquez, J. Guerrero, J. Miret, M. Castilla, and L. de Vicuñanda, "Hierarchical control of intelligent microgrids," IEEE Ind. Electron. Mag., vol. 4, no. 4, pp. 23-29, Dec. 2010.

[11] P. Palensky, The JEVis Service Platform-Distributed Energy Data Acquisition and Management. Boca Raton, FL: CRC Press, 2005, pp. 111-1-111-11, no. 0849319854.

[12] A. Gabaldon, A. Molina, C. Roldan, J. Fuentes, E. Gomez, I. RamirezRosado, P. Lara, J. Dominguez, E. Garcia-Garrido, and E. Tarancon, "Assessment and simulation of demand-side management potential in urban power distribution networks," in IEEE Proc. Tech. Conf. Power Tech Conf., Bologna, 2003, vol. 4, p. 5.

[13] E. Koch, P. Palensky, M. A. Piette, S. Kiliccote, and G. Ghatikar, "Architecture for supporting the automation of demand response," presented at the 1st IEEE Ind. Electron. Soc. Industry Forum, Santa Clara, CA, 2008.

[14] R. Yin, P. Xu, M. Piette, and S. Kiliccote, "Study on auto-DR and pre-cooling of commercial buildings with thermal mass in California," Energy and Buildings, vol. 42, no. 7, pp. 967-975, Jan. 2010.

[15] D. Westermann and A. John, "Demand matching wind power generation with wide-area measurement and demand-side management," IEEE Trans. Energy Conversion, vol. 22, no. 1, pp. 145-149, 2007.

[16] F. De Ridder, M. Hommelberg, and E. Peeters, "Four potential business cases for demand side integration," in Proc. 6th Eur. Int. Conf. Energy Market, EEM'09, May 2009, pp. 1-6.

[17] M. Stadler, P. Palensky, B. Lorenz, M. Weihs, and C. Roesener, "Integral resource optimization networks and their techno-economic constraints," Int. J. Distrib. Energy Syst., vol. 1, no. 4, pp. 299-320, Oct. 2005.

[18] L. Cantin, M. Deschenes, B. Comeau, and M. D. Amours, "Controller for controlling operation of at least one electrical load operating on an ac supply, and a method thereof," U.S. Patent 5442 335, 1995.

[19] F. Kupzog and P. Palensky, "Wide-area control systems for balance-energy provision by energy consumers," in Proc. IFAC, FET'07, Toulouse, France, 2007, pp. 337-345.

[20] W. Qureshi, N.-K. Nair, and M. Farid, "Demand side management through efficient thermal energy storage using phase change material," in Proc. Power Eng. Conf., AUPEC'08, Australasian Universities, 2008, pp. 1-6.

[21] C. Webb, "Virtual power plants: Making the most of distributed generation," Power Eng. Int., vol. 18, no. 7, pp. 28-31, 2010.

[22] IEC 61850 Series, IEC Standard 61 850, IEC, 2010.

[23] I. Gyuk, P. Kulkarni, J. Sayer, J. Boyes, G. Corey, and G. Peek, "The united states of storage [electric energy storage]," IEEE Power and Energy Mag., vol. 3, no. 2, pp. 31-39, Mar. 2005.

[24] T.-J. Park and S.-H. Hong, "Experimental case study of a bacnet-based lighting control system," IEEE Trans. Autom. Sci. Eng., vol. 6, no. 2, pp. 322-333, Apr. 2009.

[25] ZigBee Smart Energy Profile, ZigBee Alliance Std., 2008, R. Simpson.

[26] S. T. Bushby, "Bacnet: A standard communication infrastructure for intelligent buildings," Autom. Construction, vol. 6, no. 5/6, pp. 529-540, Sep. 1997.

[27] BACnet Load Control Object, ISO Sttandard ISO 16 484-5 Add-1352004e, ISO, 2004.

[28] T. Handa, A. Oda, T. Tachikawa, J. Ichimura, Y. Watanabe, and H. Nishi, "Knives: A distributed demand side management system-Integration with zigbee wireless sensor network and application," in Proc. 6th IEEE Conf. Ind. Informat, INDIN'08, 2008, pp. 324-329.
[29] S. Darby, The effectiveness of feedback on energy consumption. A review for Defra of the literature on metering, billing and direct displays Environmental Change Inst., Univ. Oxford, Oxford, U.K., 2006, Tech. Rep..

[30] F. Saffre and R. Gedge, "Demand-side management for the smart grid," in Proc. IEEE/IFIP Network Oper. Manage. Symp. Workshops (NOMS Wksps), Apr. 2010, pp. 300-303.

[31] R. Lasseter, J. Eto, B. Schenkman, J. Stevens, H. Vollkommer, D. Klapp, E. Linton, H. Hurtado, and J. Roy, "Certs microgrid laboratory test bed," IEEE Trans. Power Delivery, vol. 26, no. 1, pp. 325-332, Jan. 2011.

[32] S. Gordon, "Supergrid to the rescue," Power Eng., vol. 20, no. 5, pp. 30-33, October 2006.

[33] W. Granzer, F. Praus, and W. Kastner, "Security in building automation systems," IEEE Trans. Ind. Electron., vol. 57, no. 11, pp. 3622-3630, Nov. 2010.

[34] A. Treytl, P. Palensky, and T. Sauter, "Security considerations for energy automation networks," presented at the 6th IFAC Int. Conf. Fieldbus Systems and their Applications (FeT 2005), Puebla, Mexico, 2005, no. 9076019096.

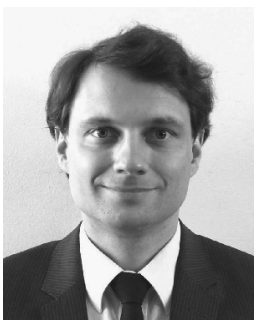

Peter Palensky (M'03-SM'05) is Head of the Business Unit for Sustainable Building Technologies at the Austrian Institute of Technology (AIT), Vienna, Austria. Prior to this, he was CTO of Envidatec Corporation, Hamburg, Germany, Associate Professor at the Department of Electrical, Electronic and Computer Engineering, University of Pretoria, South Africa, University Assistant at the Vienna University of Technology, Austria, and Researcher at the Lawrence Berkeley National Laboratory, CA. His main research fields are automation networks, distributed embedded systems, home and building automation and energy management.

Dr. Palensky is an elected AdCom Member of the Industrial Electronics Society of the IEEE. He is active in international committees like ISO, IEEE, and CEN.

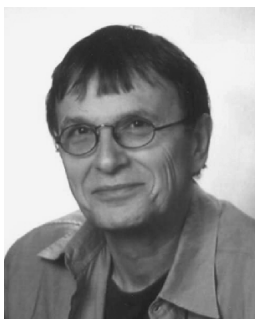

Dietmar Dietrich (SM'04) became Professor of Computer Technology at the Vienna University of Technology, Vienna, Austria, in 1992. He had been Head of the Institute of Computer Technology since 1999. Prior to this, he worked in the aviation and space industry, and later in the communication industry. $\mathrm{He}$ is a member (member of the advisory board, chair, convenor, etc.) of various national and international organizations and also a delegate of the OVE and ON in CEN and CENELEC. He is and was Associated Editor for the IEEE TRANSACTIONS ON INDUSTRIAL INFORMATICS (TII) and for the IEEE TRANSACTIONS ON INDUSTRIAL ELECTRONICS (TIE).

Dr. Dietrich is an IEEE IES AdCom member, initiator as well as past TC Chair of BACM (Building Automation, Control and Management) in IES/IEEE. Furthermore, he is Associate Editor for EURASIP and co-organizer of various tracks and conferences for the IEEE. He also became a member of the board of the OVE in 2002 and was Vice President until Spring 2008. He was Chair of Section Austria in IEEE R8 from 2006 to 2008. In 1994, he founded the Center of Excellence for Fieldbus Systems, and in 1995, the International Biennial Fieldbus Conference FeT. He organized national and international workshops and conferences for IEEE and IFAC. 